\title{
The Macaulay Duration: A Key Indicator for the Risk-Adjustment in Fair Value
}

\author{
Francesca Beccacece ${ }^{1}$, Roberto Tasca $^{2} \&$ Luisa Tibiletti ${ }^{3}$ \\ ${ }^{1}$ Department of Decision Sciences, Bocconi University, Milano, Italy \\ ${ }^{2}$ Department of Management, University of Bologna, Bologna, Italy \\ ${ }^{3}$ Department of Management, University of Torino, Torino, Italy \\ Correspondence: Luisa Tibiletti, Department of Management, University of Torino, Corso Unione Sovietica \\ 218/bis, 10134 Torino, Italy. E-mail: luisa.tibiletti@unito.it
}

Received: October 20, 2018

doi:10.5539/ijbm.v13n12p251
Accepted: November 17, $2018 \quad$ Online Published: November 21, 2018

URL: https://doi.org/10.5539/ijbm.v13n12p251

\begin{abstract}
International Financial Reporting Standards (IFRS) 13 Fair Value Measurement lays down two methods to adjust Expected Present Value (EPV) for risk. According to Method 1, expected cash inflows should be risk-adjusted by subtracting a risk-premium and discounted at the market risk-free rate, see (IFRS 13, B25). In contrast according to Method 2, expected cash inflows should be discounted at the risk-free rate augmented by a risk-premium addendum, see (IFRS 13, B26). Standard IFRS 13, B29 leaves the freedom to choose between the two methods. The aim of this note is to identify the relationship between the Risk-Adjusted EPVs rolled out from Method 1 and Method 2. First we introduce a theoretical solution to risk-adjustments compliant with the Standard IFRS 13, B29. Then, we set up a user-oriented proxy to connect the risk-premium present in Method 1 with the risk-adjusted rate present in Method 2. This proxy spots light on the key role played by the Macaulay Duration of expected inflows, rather than that of the lifetime of the project. As a consequence, projects expiring at the same redemption date and endowed with the same EPV and/or the same total inflow may differ considerably in risk-adjustments, due to different Macaulay Durations. A user-oriented method to properly to fast evaluate risk-adjustments for multi-cash inflow projects is provided. Sensitivity analysis of the impact of the Macaulay Duration on Risk-Adjusted EPV is also rolled out through numerical examples.
\end{abstract}

Keywords: fair value, financial statements' comparability, macaulay duration, risk-adjusted epv methods, risk-adjusted rate, risk premium

\section{Introduction}

International Financial Reporting Standard 13 (IFRS 13) Fair Value Measurement defines the fair value as the 'price that would be received to sell an asset or paid to transfer a liability in an orderly transaction in the principle (or the most advantageous) market at the measurement date'. Since January 2013 IFRS 13 is mandatory. Fair Value View is the most effective way to satisfy lenders and investors needs of information in their process of financial resources allocation, as stated in Whittington $(2008,2015)$. Their needs will be served because: 'Investors', lenders' and other creditors' expectations about returns depend on their assessment of the amount, timing and uncertainty of (the prospects for) future net cash inflows to the entity.' (Conceptual Framework OB3).

IFRS 13 defines fair value as "the standard" in market valuation and examines consequences from the application of this "standard", when, in valuating assets and liabilities, no directly observable market information is available.

This paper analyzes how it is possible to create a correspondence between different methods in order to determine Expected Present Value (EPV) under conditions of uncertainty, within the fair value (FV) definition.

Since in the Conceptual Framework for Financial Reporting (2010, revised in 2018), jointly designed by IASB and IFRICs, comparability is established as one of the qualitative characteristics of useful financial information, this article applies the principle within the methods for the definition of the EPV when risk adjustment techniques are required.

IFRS 13 establishes that, without directly observable market prices, the need is to proceed through valuation 
models. However, those financial models must take into account all inputs directly observable from the market, in accordance with the "fair value hierarchy", which results in a market-based, rather than entity-specific, measurement. As part of this assumption, in IFRS 13 a differentiation is envisaged in relation to the evaluation method that can be used to determine the FV (Paragraph 62).

Therefore, it is crucial to recognize a non-objective dimension in the principle, reflected in the choice the individual will take in selecting a model to determine the FV, out of the market evaluation. It addresses the issue of how to include the risk profile in determining the instrument financial value. Specifically, in the "income approach" for the EPV determination, the evaluator deals with uncertainty issues that in the market are assessed by the risk premium.

The provision of Method 1 and Method 2 (B25 and B26) for measuring the risk premium on expected cash flows displays a significant issue, leading to the review of the logical architecture of the Conceptual Framework, if any kind of comparison should not be feasible.

Besides comparability, some other qualitative characteristics for useful financial information are relevant. KPMG (2010) highlights that: "The Framework provides a broad discussion of the basis of preparing financial statements. It discusses the objectives of financial statements; their underlying assumptions and qualitative characteristics, such as relevance and reliability." And it adds that: "In many cases there is a trade-off between relevance and reliability of information...".

We specifically face this trade-off in the determination of the EPV. In fact, according to Method 1, the determination of the EPV proceeds by adjusting expected cash flows for the risk premium and then realizes the discounting process by applying a risk-free rate. According to Method 2, the EPV is determined by discounting unadjusted risky cash flows by means of discount rates that incorporate the risk premium required by market participants.

The existence of the two Methods and the required reliability for evaluations lead to a comparison of the assumptions on risk adjustment techniques (B17). IFRS 13 establishes that must be evident the link existing between the cash flows and the discount rate. Thus, if the considered cash flows are generated on a contract basis, similar to ones of other deals in an efficient market, it is correct discounting with the implicit rates of the contracts already traded on the market. If the cash flows are produced by an activity that does not have similar financial profile with other market traded contracts, a need to estimate a specific risk premium for the activity arises, in order to maximize its comparability with other activities traded on the market. This issue arises when the cash flows are not fixed in the contract, but result from the operators' expectations. It set a realistic problem of comparability among institutions' financial statements.

For all these reasons, it is crucial to have a comparison tool, which allows to attain the compliance of Methods 1 and Method 2 with IFRS 13.

The contribution of this article supports this aim. The Macaulay Duration is just that tool to compare the results of Method 1 and Method 2, understanding and deepening the reasons for any differences.

First we state a general Risk-Adjusted EPV formula complaint with IFRS 13, B29.

Second, we provide a proxy solution that spotlights the direct relation between the cash risk-premium used in EPV Method 1 (IFRS 13, B25) and the risk-premium rate used in EPV Method 2 (IFRS 13, B26).

We show that the Macaulay Duration of expected cash inflows, rather than the lifetime of the project, is the key driver in risk adjustments.

The remainder of the paper is organized as follows. In Section 2, we discuss the Standards IFRS 13, B25 and IFRS 13, B26. In Section 3 the compliance condition with IFRS 13, B29 is settled. In Section 4 main results are discussed. In Section 5 the results are illustrated using numerical examples. Section 6 concludes the note.

\section{Method 1 and Method 2 for computing Risk-Adjusted EPV}

IFRS 13, B17 commands to adjust EPV for risk according to one of the two risk-adjusting techniques:

- EPV Method 1 (IFRS 13, B25) adjusts the expected inflows by subtracting a cash risk-premium. That method is grounded on the actuarial certainty-equivalent principle that commands that uncertain expected value should be depreciated by a risk-premium, whose amount depends on the decision maker risk aversion. Finally, risk-adjusted cash inflows are to be discounted at the market risk-free rate.

- EPV Method 2 (IFRS 13, B26) prescribes to discount the expected cash flow at the risk-free rate augmented by a risk-premium addendum. 
Standard IFRS 13, B29 leaves free to choose between Method 1 or Method 2 to adjust EPV for risk and compute the so called fair value.

We lay out the notation used throughout the paper. Let

- $\quad a_{s} \geq 0$ is the expected value of the uncertain cash inflow of the project $A$, at time $t_{s}, s=1, \ldots, n$;

- $\quad i$ is the market risk-free rate (Note 1);

- $\quad r$ is the risk-premium rate;

- $\quad N P V_{A}(i)=\sum_{s=1}^{n} \frac{a_{s}}{(1+i)^{t_{s}}}$ is the Net Present Value (NPV) of the expected cash inflows $a_{s}, s=1, \ldots, n$ discounted at the interest rate $i$. It is also called the Expected Present Value (EPV) of the project $A$;

- $\quad p_{s} \geq 0$ is the cash risk-premium to be subtracted to the expected inflow $a_{s}$ at time $t_{s}, s=1, \ldots, n$;

- $\quad N P V_{P}(i)=\sum_{s=1}^{n} \frac{p_{s}}{(1+i)^{t_{s}}}$ is the $N P V$ of the risk-premium $p_{s}$ cash flow discounted at the market risk-free interest rate $i$;

- $D=D(i)=\frac{\sum_{s=1}^{n} t_{s} \cdot a_{s} \cdot(1+i)^{-t_{s}}}{\sum_{s=1}^{n} a_{s} \cdot(1+i)^{-t_{s}}}$ is the Macaulay Duration discounted at the market risk-free rate $i$ (see Macaulay, 1938; for a discussion on the use of bond duration see for example Fabozzi, 1999) (Note 2). For simplicity but without loss of generality, we assume initial time $t_{0}=0$.

\subsection{EPV Method 1 (IFRS 13, B25)}

EPV Method 1 (IFRS 13, B25) relies on the framework of the Certainty Equivalent, widely discussed in the literature (see Fishburn, 1986; Chen, 1967; Mao, 1970). The expected inflow $a_{s}$ is diminished by the cash risk-premium $p_{s}$, for $s=1, \ldots, n$. Under the assumption that the uncertain inflows of the project $A$ are stochastically independent (Note 3), the Risk-Adjusted EPV can be simply calculated as the sum of the discounted risk-adjusted expected cash inflow $\left(a_{s}-p_{s}\right)$, for $s=1, \ldots, n$, then

$$
\text { Risk-Adjusted EPV } 1=\sum_{s=1}^{n} \frac{a_{s}-p_{s}}{(1+i)^{t_{s}}}=\sum_{s=1}^{n} \frac{a_{s}}{(1+i)^{t_{s}}}-\sum_{s=1}^{n} \frac{p_{s}}{(1+i)^{t_{s}}}=N P V_{A}(i)-N P V_{P}(i)
$$

\subsection{EPV Method 2 (IFRS 13, B26)}

According to EPV Method 2 (IFRS 13, B26), the expected cash inflows $a_{s}, s=1, \ldots, n$ should be discounted at the risk-free rate $i$ augmented by a risk-premium addendum $r$. It results

$$
\text { Risk - Adjusted } E P V_{2}=\sum_{s=1}^{n} \frac{a_{s}}{(1+i+r)^{t_{s}}}=N P V_{A}(i+r)
$$

where $i+r$ is the risk-adjusted rate of interest.

Method 1 and 2 lead to the same Risk-Adjusted EPV value if (and only if)

$$
\text { Risk-Adjusted EPV }=\text { Risk - Adjusted EPV }
$$

i.e.

$$
N P V_{A}(i)-N P V_{P}(i)=N P V_{A}(i+r) .
$$

Equation (1) can be called the condition for compliance with IFRS 13, B29. In general, formula (1) cannot be solved to come up an explicit expression of the risk-premium rate $r$ as a function of the cash-risk premium $p_{s}$, for $s=1, \ldots, n$. A user-oriented proxy of such relation will be achieved in Section 3 .

\section{The role of the Macaulay Duration in Risk-Adjustments}


First, we tackle the case of projects with a single-cash inflow. The both explicit and a proxy formula for the Risk-Adjusted EPV will be achieved.

\subsection{Projects with a single-Cash Inflow}

Let the project has a single-cash inflow $a_{1}$ cashable at maturity $t_{1}$. For $n=1$ the compliance condition (1) comes down to

$$
\text { Risk-Adjusted EPV }=\frac{a_{1}-p_{1}}{(1+i)^{t_{1}}}=\frac{a_{1}}{(1+i+r)^{t_{1}}}
$$

The risk-premium becomes

$$
p_{1}=a_{1}\left[1-\left(\frac{1+i}{1+i+r}\right)^{t_{1}}\right]
$$

Discounting both hand-sides of above at the market risk-free rate $i$, we obtain

$$
N P V_{p_{1}}(i)=\frac{p_{1}}{(1+i)^{t_{1}}}=\frac{a_{1}}{(1+i)^{t_{1}}} \cdot\left[1-\left(\frac{1+i}{1+i+r}\right)^{t_{1}}\right]=E P V \cdot\left[1-\left(\frac{1+i}{1+i+r}\right)^{t_{1}}\right] .
$$

So, we achieve the exact expression for

$$
\text { Risk-Adjusted } E P V=E P V-N P V_{p_{1}}(i)=E P V \cdot\left(\frac{1+i}{1+i+r}\right)^{t_{1}}
$$

The risk-adjusting factor $\varphi(i, r)=\left(\frac{1+i}{1+i+r}\right)^{t_{1}}$ holds the following properties:

- $\varphi<1$. That informs that the Risk-Adjusted EPV is $\varphi$ per cent of EPV. For example, if $\varphi=0.80$ that means that the Risk-Adjusted EPV is $80 \%$ of EPV;

- $\varphi$ is an increasing and convex function of the risk-free rate $i$. Therefore, the higher the risk-free rate $i$, the higher $\varphi$ and the lower the impact of risk-adjustments. Due to the convexity of $\varphi$, the marginal effect is increasing;

- $\varphi$ is a decreasing exponential function of the cashable date $t_{1}$. Therefore, the longer time the cashable date $t_{1}$, the lower $\varphi$ and the stronger the impact on risk-adjustments.

The following linear approximation of (3) shows up the key drivers in risk-adjustments

$$
\text { Risk-Adjusted } E P V \approx E P V \cdot\left(1-t_{1} \cdot \frac{r}{1+i}\right)
$$

see the proof in the Appendix A. If there is a single expected cash-inflow $a_{1}$ cashable at $t_{1}$, the Macaulay Duration $D=t_{1}$. Above can be rewritten as

$$
\text { Risk Adjusted } E P V \approx E P V \cdot\left(1-D \cdot \frac{r}{1+i}\right)
$$

In the special case of $D=t_{1}=1$ year, the risk-premium becomes

$$
p_{1}=a_{1} \frac{r}{1+i+r}
$$

It comes down

$$
N P V_{p_{1}}(i)=E P V \cdot \frac{r}{1+i+r}
$$


and the exact expression (3) becomes

$$
\text { Risk-Adjusted } E P V=E P V \cdot\left(\frac{1+i}{1+i+r}\right)
$$

And the linear approximation

$$
\text { Risk Adjusted } E P V \approx E P V \cdot\left(1-\frac{r}{1+i}\right)=E P V \cdot \frac{1+i-r}{1+i}
$$

\subsection{Projects with Multi-Cash Inflows}

Although the condition for compliance with IFRS 13, B29 can be always solved numerically, a general solution for multi-cash inflow projects is not available in closed form.

Analogously to the single-cash inflow projects, we give a linear approximation of the Risk-Adjusted according to Method 2,

$$
\text { Risk Adjusted } E P V_{2}=N P V_{A}(i+r) \approx N P V_{A}(i) \cdot\left(1-D \cdot \frac{r}{1+i}\right)
$$

Where $D=D(i)$ is the Macaulay Duration of the expected inflows $a_{s}, s=1, \ldots, n$ discounted at the market risk-free rate $i$ (see the proof in the Appendix B). Note that $D$ is a decreasing and convex function of the risk-free rate $i$. so as the risk-free rate $i$ increases, the risk-adjustments decrease.

\section{Main Results}

We are now ready to sum up our main results.

\section{Result 1}

$N P V$ of risk-premium cash flow $N P V_{P}(i)$ used in Method 1 (IFRS 13, B25) and risk-adjusted rate $r$ used in

Method 2 (IFRS 13, B26) are approximately related as follows

$$
N P V_{P}(i) \approx E P V \cdot D \cdot \frac{r}{1+i} \text {. }
$$

where $D=D(i)$ is the Macaulay Duration discounted at the market risk-free rate $i$.

Remarks on formula (8) follow:

a. One might think that projects with the same redemption date and equal EPV or equal total inflow should be risk-adjusted by similar cash-premium amounts. That conjecture is not true in general. In fact, risk-adjustments are not proportional to the lifetime of the project, but rather to the Macaulay Duration $D$ of expected inflows (see Examples 1 and 2 in Section 5).

b. Projects with the same EPV and the same Duration $D$ are risk-adjusted by approximately the same cash risk-premium NPV.

c. The relative $N P V_{P}(i)$ to $E P V$ is

$$
\frac{N P V_{P}(i)}{E P V} \approx D \cdot \frac{r}{1+i}
$$

Where $D$ plays the role of cash risk-premium elasticity in emphasizing or smoothening the EPV risk-adjustments.

\section{Result 2}

Risk-Adjusted EPV complaint with IFRS 13, B29 can be approximated by

$$
\text { Risk Adjusted EPV }=E P V \cdot\left(1-D \cdot \frac{r}{1+i}\right)
$$

where $E P V=N P V_{A}(i)$ and $D=D(i)$ is the Macaulay Duration (Note 4) discounted at the market risk-free rate $i$. Formula (10) makes evidence that the Macaulay Duration $D=D(i)$ summarises all information needed for risk-adjustments. 


\section{Result 3}

Risk-Adjusted EPV approximation (10) is always rounded down. The approximation is rather good when the risk-premium rate $r$ is small, on the contrary in the presence of large risk-premium rate $r$, the quality of the approximation deteriorates. The error magnitude is amplified or smoothened by $D$. So, cash risk-premium approximation is good for projects with short Duration, but it may flaw down for projects with long duration. Goodness-of-fit of will be tested with simulations in Section 5, Example 4.

\section{Numerical Illustrative Examples}

To ascertain the relevance of the Macaulay Duration on risk-adjustments we set a number of illustrative examples. Throughout this Section we assume that the market free-risk rate is $i=5 \%$.

\section{Example 1: Projects with equal total inflow and different Macaulay Duration}

Let the projects A, B, C, D be structured as in Table 1. Projects A, B, C, D expire in 4 years, have total inflow of $€ 2,000$ but display different $D$.

The most significant inflows (i.e. those of expected amount $€ 1,000$ and $€ 800$ ) are:

- $\quad$ at the beginning of the lifetime period for the project $\mathrm{A}$;

- at the extreme dates of the lifetime period for the project $B$;

- $\quad$ about at the middle of the lifetime period for the projects $C$ and $D$.

The Macaulay Duration of the projects A, B, C and D goes from 1.6201 years to 3.3186 years. For short $D$ (as for $D=1.6201$ years) the relative impact of the NPV of cash risk-premium on EPV is contained (of $4.56 \%$ ), in contrast for high $D$ (as for $D=3.3186$ years), the relative impact of the NPV of cash risk-premium on EPV is strong (of $9.77 \%$ ).

Table 1. Projects with total inflow of $€ 2000$ and different Macaulay Duration $D$

\begin{tabular}{lllll}
\hline & Project A & Project B & Project C & Project D \\
\hline Year 1 & 1,000 & 1,000 & 100 & 100 \\
Year 2 & 800 & 100 & 1,000 & 100 \\
Year 3 & 100 & 100 & 800 & 800 \\
Year 4 & 100 & 800 & 100 & 1,000 \\
Total inflows & 2,000 & 2,000 & 2,000 & 2,000 \\
$\begin{array}{l}\text { D expressed in years } \\
\text { EPV at } i=5 \%\end{array}$ & $\mathbf{1 . 6 2 0 1}$ & $\mathbf{2 . 2 5 1 9}$ & $\mathbf{2 . 4 2 8 2}$ & $\mathbf{3 . 3 1 8 6}$ \\
$\begin{array}{l}\text { Risk }- \text { Adjusted } E P V_{2} \\
\text { with } i=5 \% \text { and } r=3 \%\end{array}$ & $1,846.6585$ & $1,787.6296$ & $1,775.6079$ & $1,699.7136$ \\
$\begin{array}{l}\text { Cash risk.-premium } \\
\text { Cash risk-premium NPV \% } \\
\text { on EPV }\end{array}$ & $1,764.6832$ & $1,679.0669$ & $1,658.5002$ & $1,548.4221$ \\
\hline
\end{tabular}

In conclusion, even Projects A, B, C and D have the same total inflows and maturity, risk-adjustments are very different, because of different Macaulay Durations.

\section{Example 2: Multi-cash inflow projects with equal EPV and different Macaulay Durations}

Let the projects E, F, G and H be structured as in Table 2. Projects E, F, G and H expire in 4 years, have EPV of about $€ 1000$ and have the Macaulay Duration of about 1, 2, 3 and 4. 
Table 2. Projects with similar EPV and different Duration D

\begin{tabular}{|c|c|c|c|c|}
\hline & Project E & Project F & Project G & Project $\mathbf{H}$ \\
\hline Year 1 & $1,049.5000$ & 542.6000 & 140.8000 & 1.0000 \\
\hline Year 2 & 0 & 200.0000 & 90.3000 & 0 \\
\hline Year 3 & 0 & 100.0000 & 500.0000 & 0 \\
\hline Year 4 & 0.5790 & 262.0000 & 428.0000 & 1214.3500 \\
\hline Total inflows & $1,050.0790$ & $1,104.6$ & $1,159.1$ & 1215.3500 \\
\hline$D$ expressed in years & 1.0014 & 2.0007 & 3.0020 & 3.9971 \\
\hline EPV at $i=5 \%$ & $1,000.0002$ & $1,000.0996$ & $1,000.0355$ & $1,000.0011$ \\
\hline $\begin{array}{l}\text { Risk-Adjusted } E P V_{2} \\
\text { with } i=5 \% \text { and } r=3 \%\end{array}$ & 27.8153 & 945.8362 & 919.2970 & 893.5094 \\
\hline Cash risk-premium NPV & 1.0014 & 54.2634 & 80.7385 & 106.4917 \\
\hline NPV of cash risk premium \% on EPV & $2.86 \%$ & $5.74 \%$ & $8.78 \%$ & $11.92 \%$ \\
\hline
\end{tabular}

In conclusion, even Projects E, F, G, and H have the same EPV and maturity, risk-adjustments required by IFRS 13, B29 differ considerably. The impact of the NPV of the cash risk-premium on EPV goes from $2.86 \%$ to $11.92 \%$.

\section{Example 3: Single-cash inflows with and different Macaulay Durations}

Let now consider single-cash inflow projects I, L, M and N with EPV of $€ 1000$, collected in Table 3 . These projects have the same EPV and Macaulay Duration of the multi-cash inflow projects E, F, G and H, collected in Table 2.

Data in Table 3 make evidence how the single-cash inflow projects I, L, M and N replicate the multi-cash inflow project E, F, G and H, respectively, that has the same EPV of $€ 1,000$ and the same Duration (Note 5). That shows that any multi-cash inflow project can be replicated by a proper single-cash inflow project.

Table 3. Risk-adjusted EPV of single-cash projects with EPV of $€ 1,000$

\begin{tabular}{lllll}
\hline & Project I & Project L & Project M & Project N \\
\hline Year 1 & 1,050 & 0 & 0 & 0 \\
Year 2 & 0 & $1,102.50$ & 0 & 0 \\
Year 3 & 0 & 0 & $1,157.6250$ & 0 \\
Year 4 & 0 & 0 & 0 & $1,215.5063$ \\
EPV at $\boldsymbol{i}=\mathbf{5 \%}$ & $\mathbf{1 , 0 0 0}$ & $\mathbf{1 , 0 0 0}$ & $\mathbf{1 , 0 0 0}$ & $\mathbf{1 , 0 0 0}$ \\
$\begin{array}{l}\text { Dexpressed in years } \\
\text { Risk }- \text { Adjusted } E P V\end{array}$ & 1 & 2 & 3 & 4 \\
with $i=5 \%$ and $r=3 \%$ & 972.2222 & 945.2160 & 918.9600 & \\
NPV of cash risk-premium & 27.7778 & 54.7640 & 81.0400 & \\
NPV of cash risk-premium \% & $\mathbf{2 . 8 6 \%}$ & $\mathbf{5 . 8 0 \%}$ & $\mathbf{8 . 8 2 \%}$ & $\mathbf{1 1 . 9 3 \%}$ \\
on EPV & & & & \\
\hline
\end{tabular}

\section{Example 4 Goodness-of-fit of the Risk-Adjusted EPV approximation}

To test the significance of the approximation (10) we calculate the approximation error at different risk-premium rates for the projects A, B, C, D defined in Table 1 . 
Table 4. Risk-adjusted EPV approximation (10) with risk-premium rates $r=1 \%, r=2 \%$ and $\quad r=3 \%$.

\begin{tabular}{|c|c|c|c|c|}
\hline & Project A & Project B & Project C & Project D \\
\hline$D$ expressed in years & 1.6201 & 2.2519 & 2.4282 & 3.3186 \\
\hline \multicolumn{5}{|l|}{ If $r=1 \%$} \\
\hline $\begin{array}{l}\text { Risk-Adjusted EPV proxy } \\
\text { formula (8) }\end{array}$ & $1,818.1646$ & $1,749.2907$ & $1,734.5452$ & $1,645.9930$ \\
\hline \multirow{2}{*}{$\begin{array}{l}\text { Exact Risk-Adjusted } E P V_{2} \\
\text { Error }\end{array}$} & $1,818.5647$ & $1,750.0327$ & $1,735.2409$ & $1,647.1284$ \\
\hline & 0.4000 & 0.7420 & 0.6957 & 1.1354 \\
\hline \multicolumn{5}{|l|}{ If $r=2 \%$} \\
\hline \multicolumn{5}{|l|}{$\begin{array}{l}\text { Risk-Adjusted EPV proxy } \\
\text { formula (8) }\end{array}$} \\
\hline \multirow{2}{*}{$\begin{array}{l}\text { Exact Risk-Adjusted EPV } \\
\text { Error }\end{array}$} & $1,791.2497$ & $1,713.8693$ & $1,696.2245$ & $1,596.7353$ \\
\hline & 1.5790 & 2.9175 & 2.7421 & 4.4630 \\
\hline \multicolumn{5}{|l|}{ If $r=3 \%$} \\
\hline \multicolumn{5}{|l|}{$\begin{array}{l}\text { Risk-Adjusted EPV proxy } \\
\text { formula (8) }\end{array}$} \\
\hline \multirow{2}{*}{$\begin{array}{l}\text { Exact Risk-Adjusted } E P V_{2} \\
\text { Error }\end{array}$} & $1,764.6832$ & $1,679.0669$ & $1,658.5002$ & $1,548.4221$ \\
\hline & 3.5064 & 6.4540 & 6.0805 & 9.8704 \\
\hline
\end{tabular}

Risk-Adjusted EPV approximation (10) is always rounded down respect to the exact solution of equation (1), because NPV is a decreasing and convex function of the interest rate used in discounting. Goodness-of-fit is sensitive to the scale of the risk-premium rate $r$. Data in Table 4 show that approximation is rather good when the risk-premium rate $r$ is small (around 1\%), while it may deteriorate for higher $r$. Approximation error is also sensitive to $D$. For long $D$ the absolute error is amplified, for short $D$ the absolute error is smoothened.

To improve the goodness-of-fit is sufficient to go on with higher order approximations. The second order approximation involves the so-called (bond) convexity index (for the notion of bond convexity, see for example Fabozzi, 1999).

\section{Conclusions}

Standard IFRS 13, B29 leaves freedom to risk-adjust EPV with Method 1 (IFRS 13, B25) or Method 2 (IFRS 13 , B26). A general formula that makes these two methods equivalent, is set up. Although this formula is always numerically computable, a closed-end expression that relates cash risk-premium present in Method 1 with risk-premium rate present in Method 2, is not achievable for multi-period projects. So we settle a user-oriented proxy that spotlights on the key drivers in risk-adjustment methods.

The main result of this note is that we make evidence that the Risk-Adjusted EPV is approximatively proportional to the Macaulay Duration of the expected inflows, rather than to the lifetime of the project. It follows that projects expiring at the same redemption date and having the same EPV and/or the same total inflow, may considerably differ in risk-adjustments. Illustrative numerical examples support our findings.

\section{References}

Bornholt, G. (2017). What is an Investment Project's Implied Rate of Return? Abacus, 53(4), 513-526. https://doi.org/10.1111/abac.12093

Chen, H.Y. (1967). Valuation under Uncertainty. Journal of Financial and Quantitative Analysis, (2), 313-325.

Fabozzi, Frank J. (1999). Duration, Convexity, and Other Bond Risk Measures.

Fishburn P.C. (1986). Implicit mean value and certainty equivalence. Econometrica, 54(5), 1197-1205. https://www.jstor.org/stable/1912328

https://www.jstor.org/stable/2329638

IASB. (2010). The Conceptual Framework for Financial Reporting.

IASB. (2011). IFRS 13, Fair Value Measurement.

KPMG. (2010). Insight into IFRS - Practical guide to International Financial Reporting Standard (7th ed.).

Macaulay, F. R. (1938). Some theoretical problems suggested by the movements of interest rates, bond yields, and stock prices in the United States since 1856. New York: Columbia University Press. 
Mao, J. C. T. (1970). Survey of Capital Budgeting: Theory and Practice. Journal of Finance, 25(3), 349-360. https://www.jstor.org/stable/2325481

McNeil, A., Frey, R., \& Embrechts, P. (2015). Quantitative Risk Management: Concepts, Techniques, and Tools. Princeton Series in Finance.

Robichek, A., \& Myers, S. (1966). Conceptual Problems in the Use of Risk- Adjusted Discount Rates. Journal of Finance, 21(5), 727-730. https://doi.org/10.1111/j.1540-6261.1966.tb00277.x

Whittington, G. (2008). Fair Value and the IASB/FASB Conceptual Framework Project: An Alternative View. Abacus, 44(2), 139-168. https://doi.org/10.1111/j.1467-6281.2008.00255.x

Whittington, G. (2015). Measurement in Financial Reporting: Half a Century of Research and Practice. Abacus, 51(4), 549-571. https://doi.org/10.1111/abac.12061

\section{Notes}

Note 1. It is worthwhile noting that the interest rates and the collection times $t_{s}$ for $s=1, . ., n$ must be expressed in the same unit of time, i.e. the commercial year composed of 360 days, or the effective year composed of 365 or 366 days.

Note 2. Note that the Macaulay Duration is an approximation of the implied duration recently introduced by Bornholt (2017) in the field of bipole projects.

Note 3. Under the assumption of stochastic independence among uncertain cash inflows, upper and lower bound for EPV can be found using the notion of copula (see McNeil et al, 2005).

Note 4. Formula (10) informs that risk-adjustments are approximately proportional to the yearly risk-premium rate $r$ and the time-weighted average $D$ expressed in years. The financial factor $\varphi(i, r)=\left(1-D \cdot \frac{r}{1+i}\right)$ plays the role of the linear bank discount factor used in Financial Mathematics to calculate the premium for discounting a bank bill, where $D$ is the maturity of the equivalent single-inflow project.

Note 5. Note that the Macaulay Duration of single-cash flow projects coincides with the cashable date of the single-inflow.

\section{Appendix A}

Let approximate Risk Adjusted $E P V=E P V \cdot\left(\frac{1+i}{1+i+r}\right)^{t_{1}}$ as a function of $r$.

$\frac{d \text { Risk Adjusted EPV }}{d r}=-E P V \cdot t_{1} \cdot\left(\frac{1+i}{1+i+r}\right)^{t_{1}-1} \cdot \frac{1+i}{(1+i+r)^{2}}$

$\left.\frac{d \text { Risk Adjusted EPV }}{d r}\right|_{r=0}=-E P V \cdot t_{1}$

Risk Adjusted $E P V \approx E P V \cdot\left(1-\frac{t_{1}}{1+i} \cdot r\right)=E P V \cdot\left(1-D \cdot \frac{r}{1+i}\right)$

where $D=t_{1}$ is the Macaulay Duration for projects with a single-cash inflow.

\section{Appendix B}

We want to approximate $\triangle N P V_{A}(i)=N P V_{A}(i+r)-N P V_{A}(i)$

Let differentiate $N P V_{A}(i)$ with respect to $i$. We obtain:

$N P V_{A}^{\prime}(i)=\sum_{s=1}^{n}-t_{s} a_{s}(1+i)^{-t_{s}-1}$ 
Dividing the both hand-sides by $N P V_{A}(i)=\sum_{s=1}^{n} a_{s}(1+i)^{-t_{s}}$, we get

$$
\frac{N P V_{A}^{\prime}(i)}{N P V_{A}(i)}=-(1+i)^{-1} \frac{\sum_{s=1}^{n} t_{s} a_{s}(1+i)^{-t_{s}}}{\sum_{s=1}^{n} a_{s}(1+i)^{-t_{s}}}=-\frac{D}{1+i}
$$

Whence $\frac{\Delta N P V_{A}(i)}{N P V_{A}(i)}=-\frac{D}{1+i} \Delta i+o(\Delta i)$. Since $\Delta i=r$

$$
\Delta N P V_{A}(i) \approx-\frac{D}{1+i} \cdot N P V_{A}(i) \cdot \Delta i
$$

We get

$$
N P V_{P}(i) \approx+N P V_{A}(i) \cdot D \cdot \frac{r}{1+i}
$$

Then,

$$
N P V_{A}(i+r)=N P V_{A}(i)-N P V_{P}(i) \approx N P V_{A}(i) \cdot\left(1-D \cdot \frac{r}{1+i}\right) \text {. }
$$

\section{Copyrights}

Copyright for this article is retained by the author(s), with first publication rights granted to the journal.

This is an open-access article distributed under the terms and conditions of the Creative Commons Attribution license (http://creativecommons.org/licenses/by/4.0/). 